\title{
A Brief History of the French Statistical Society (SFdS)
}

\author{
Gérard Biau, President of the SFdS
}

The French Statistical Society was founded in 1997 through the merger of two associations of statisticians: the Statistical Society of Paris (SSP) and the Association for Statistics and its Applications (ASU).

Formed in 1860, the main goal of the SSP was to "popularise statistical research through its work and publications". From the beginning, the group evolved in a way that stayed close to economists, while also being attuned to demographers, actuaries and doctors, not to mention politicians. In order to underpin its projects, the SSP published - since the year it was created - the Journal of the Statistical Society of Paris and did so regularly for nearly 140 years. This journal was then succeeded by the Journal of the French Statistical Society in the context of the merger mentioned above.

The ASU originated in a meeting of around 30 statisticians in 1969 in Toulouse. They were mainly university professors, oriented toward applied statistics and practising their profession mainly outside Paris, who wished to establish a more formal relationship. It was also a question of reflecting on the content of statistics teaching, both in university curricula and secondary school education, and to study how to participate in programme reforms.
The first action of the ASU was to organise the Statistics Days conference, which is now held every year at the end of May or the beginning of June in a different town in France or abroad. From 1976 onward, a bulletin was also published, entitled Statistics and Data Analysis. A third initiative was the creation in October 1984 of the Study Days in Statistics (JES) venture, which, every two years, offers an in-depth course for one week on a statistical subject of interest, giving rise to a book written by the speakers and organisers.

In 1987, the ASU became the Association for Statistics and its Uses in order to emphasise a turn toward applications as well as a will to interact with non-university statisticians. A second important decision concerned the idea of specialised think tanks "to encourage certain aspects of statistics in line with the aims of the association". These quickly acquired a life of their own, organising seminars, courses, specialised meetings and so on. Today, these groups are named "Agro-Industry", "Banking-Finance-Insurance", "Biopharmacy and Health", "Chemometrics", "Surveys", Models and Applications", "Teaching Statistics", "Environment and Statistics", "Reliability and Uncertainty", "History of 
Statistics, Probability and their Uses", "Young Statisticians", "Machine Learning and Artificial Intelligence", "Mathematical Statistics", "Statistics and Public Issues" and "Statistics and Sport".

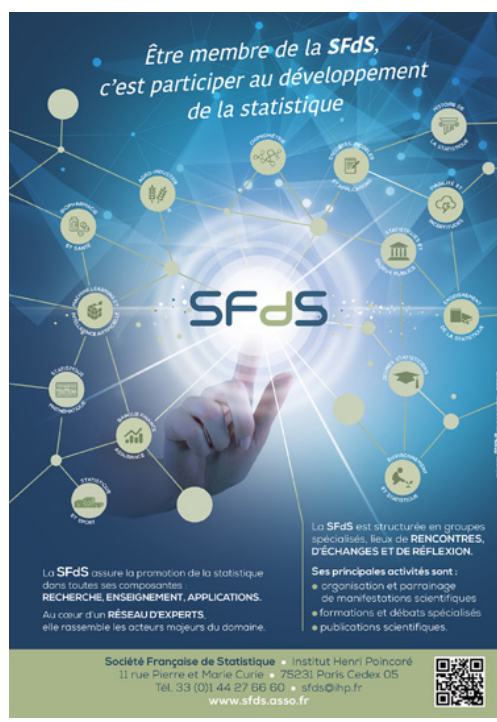

Among the first activities of the SFdS was the birth of the Journal of the French Statistical Society, which aimed to be a tool for disseminating scientific information amongst statisticians. This journal acted as an extension of the Journal of the Statistical Society of Paris (in issue numbering also) and merged in 2007 with the previously established Journal of Applied Statistics. The journal is currently published in electronic form, as are three other journals formed since: Statistics and Teaching, Statistics and Society and Case Studies in Business, Industry and Government Statistics (CSBIGS).

The SFdS also supports collections of scholarly texts. In addition to those from the Study Days in Statistics, currently published by Technip, there are also the Statistical Practice collection, published with Rennes University Press, A Fresh Look at Statistics collection, published by Technip and aimed primarily at teachers and statistics users, and finally the World of Data collection, published by EDP Sciences for a broad audience.

Note also that the SFdS gives out several awards. The oldest, the Dr Norbert Marx Award, is given every two years for applied statistical methodology work in the fields of epidemiology, public health and health economics. Since 2004, there is also the Marie-Jeanne LaurentDuhamel Award, rewarding doctoral theses in statistics defended in the preceding three years. The jury awards this prize once every three years to work in theoretical statistics and the following year to applied statistics. In the third year, the award is replaced by an homage - the Pierre Simon de Laplace Prize - to an experienced statistician whose contribution to the French statistics community has been particularly remarkable.

It should also be mentioned that the SFdS and the learned societies that preceded it were the originators of both the European Courses in Advanced Statistics (ECAS) in 1987 and the Federation of European National Statistical Societies (FENStatS) in 2014. The SFdS also organises training courses and debates, such as the Statistical Workshops, the Statistics Café and the Young Statisticians Meeting.

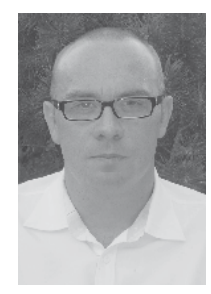

Gérard Biau is a full professor at the Probability, Statistics and Modelling Laboratory (LPSM) of Sorbonne University, Paris. He is Deputy Director of LPSM and has served as the President of the French Statistical Society (SFdS) since 2015. He is an elected member of the International Statistical Institute and was a member of the prestigious Institut Universitaire de France from 2012 to 2017. His research is mainly focused in developing new methodology and rigorous mathematical theory in statistical learning, artificial intelligence and massive and high-dimensional data, whilst trying to find connections between statistics and algorithms. Gérard Biau has co-authored two books and more than 60 articles and research notes in international, peer-reviewed journals and he has been the PhD advisor of 17 students. 